\title{
ESTUDO DA LABILIDADE DE Cu(II), Cd(II), Mn(II) E Ni(II) EM SUBSTÂNCIAS HÚMICAS AQUÁTICAS UTILIZANDO-SE MEMBRANAS CELULÓSICAS ORGANOMODIFICADAS
}

\author{
André Henrique Rosa*, Danielle Goveia, Iramaia C. Bellin, Paulo Sérgio Tonello e Maria Lúcia Pereira Antunes \\ Departamento de Engenharia Ambiental, Universidade Estadual Paulista, Av. 3 de março, 511, 18087-180 Sorocaba - SP, Brasil \\ Newton Luiz Dias Filho \\ Departamento de Física e Química, Universidade Estadual Paulista, 15385-000 Ilha Solteira - SP, Brasil \\ Ubirajara Pereira Rodrigues Filho \\ Instituto de Química de São Carlos, Universidade de São Paulo, 13560-970 São Carlos - SP, Brasil
}

Recebido em 21/11/05; aceito em 11/4/06; publicado na web em 30/8/06

\begin{abstract}
LABILITY STUDY OF Cu(II), Cd(II), Mn(II) AND Ni(II) COMPLEXED BY AQUATIC HUMIC SUBSTANCES USING ORGANOMODIFIED CELLULOSE MEMBRANES. In this work commercial filters papers were organomodified with tetraethylorthosilicate (TEOS) and 3-aminopropyltriethoxysilane (3-APTS), aiming at the development of a new analytical procedure for in-situ speciation of labile and inert metal species in aquatic systems. Parameters that exert influence on the metal lability such as $\mathrm{pH}$, chelating time, concentration and characteristics of the organic matter were studied in the laboratory using tests for metal recuperation. The results showed slower kinetics for $\mathrm{Cu}$ ion than for $\mathrm{Ni}, \mathrm{Mn}$ and $\mathrm{Cd}$ in the absence of aquatic humic substances (AHS). The relative lability observed for complexed metals in aquatic humic substances using organomodified filter papers was $\mathrm{Cu}>\mathrm{Cd}>\mathrm{Ni}>\mathrm{Mn}$. The $\mathrm{pH}$ values, structural characteristics and concentration of AHS exert strong influence on the lability of the metals. The results obtained showed that the utilization of organomodified filter papers can be an interesting and promising alternative for in situ characterization of metal lability in aquatic systems.
\end{abstract}

Keywords: water; aquatic humic substances; metal.

\section{INTRODUÇÃO}

Cerca de $20 \%$ da matéria orgânica natural (MON) nos ecossistemas naturais consiste de compostos orgânicos com estruturas químicas definidas, tais como carboidratos, aminoácidos e hidrocarbonetos. Os $80 \%$ restantes correspondem à matéria orgânica detrítica, pertencentes a um grupo de estrutura química indefinida, com tempo de residência mais longo no ambiente e relativamente resistente à degradação, denominada matéria orgânica refratária (MOR) ${ }^{1}$. Os principais constituintes da MOR globalmente distribuídos nos sistemas aquáticos e terrestres são definidos operacionalmente por substâncias húmicas $(\mathrm{SH})$. Estas são formadas por processos microbiológicos, pela decomposição de resíduos de plantas e animais, sendo constituídas por uma grande variedade de sub-estruturas alifáticas e aromáticas ${ }^{2}$.

Devido as suas propriedades físico-químicas polieletrolíticas, as $\mathrm{SH}$ exercem grande influência no comportamento de metais em ambientes aquáticos ${ }^{3-5}$. Nestes, íons metálicos e substâncias húmicas aquáticas (SHA) apresentam variadas ligações e os metais podem se distribuir em complexas trocas entre solução e fase sólida. Transporte, complexação, (bio-)disponibilidade e ação de metais no ambiente dependem também da estabilidade do complexo SHA-Metal. A estabilidade das espécies SHA-Metal é determinada por uma série de fatores, incluindo o número de átomos que formam a ligação com o metal, a natureza e a concentração do íon metálico, concentração/característica das SHA, $\mathrm{pH}$, tempo de complexação etc. ${ }^{2,6,7}$.

Desta forma, informações associadas à labilidade de metais, às transformações e à estabilidade de complexos SHA-Metal são importantes para o entendimento de processos biogeoquímicos que ocorrem no ambiente. Com esta finalidade, várias metodologias/procedimentos têm sido propostos, utilizando-se técnicas eletroquímicas,

*e-mail: ahrosa@sorocaba.unesp.br cromatográficas e/ou trocadores iônicos para diferenciação de metais lábeis e inertes em sistemas aquáticos ${ }^{8-10}$. Entretanto, a grande maioria destes estudos têm sido desenvolvidos em laboratório, após amostragem, armazenamento e tratamento das amostras de água, utilizando-se modelos de interpretação simplistas baseados em reações com "soluções puras", freqüentemente contendo apenas um ligante e um ou alguns metais. É indiscutível que estes modelos têm contribuído para a compreensão das reações de complexação de metais por ligantes simples, porém, a utilização desses modelos para a compreensão de fenômenos ambientais em sistemas aquáticos, os quais contêm uma grande variedade de ligantes (hidro)coloidais, polieletrólitos e polifuncionais é questionável ${ }^{11,12}$.

Este trabalho apresenta o desenvolvimento de um novo procedimento analítico que pode ser aplicado in situ, para diferenciação de espécies metálicas lábeis e inertes. Este procedimento está baseado na organomodificação de filtros de papel celulósicos de filtração rápida, utilizando-se tetraetilortossilicato (TEOS) e 3aminopropiltrietoxissilano (3-APTS). Após a organomodificação do papel de filtro, foi feito o estudo dos parâmetros que influenciam na labilidade relativa de metais, tais como $\mathrm{pH}$, tempo de complexação, concentração e caracterísitica de substâncias húmicas aquáticas.

\section{PARTE EXPERIMENTAL}

\section{Organomodificação dos filtros de papel}

Utilizou-se para modificação química, filtros de papel (JP41 da Jprolab-Alemanha) de filtração rápida, com $90 \mathrm{~mm}$ de diâmetro e 80 $\mathrm{g} / \mathrm{m}^{2}$. Estes foram lavados em acetona e, em seguida, durante $1 \mathrm{~min}$ em solução de hidróxido de sódio $\left(0,25 \mathrm{~mol} \mathrm{~L}^{-1}\right)$ a $40{ }^{\circ} \mathrm{C}$ para eliminar impurezas. Os filtros de papel foram deixados em etanol por no mínimo $10 \mathrm{~min}$, imersos em solução etanólica 2,2\% (v/v) de tetraetilortosilicato (TEOS, Aldrich, EUA) por $4 \mathrm{~min}$, em seguida em solu- 
ção de ácido nítrico $\left(10^{-3} \mathrm{~mol} \mathrm{~L}^{-1}\right)$ para hidrólise do TEOS e novamente imersos em etanol (98\%, Merck) por $10 \mathrm{~min}$. O ancoramento do grupo amino foi feito pela imersão em solução etanólica de 3aminopropiltrietoxissilano (3-APTS) $\left(10^{-3} \mathrm{~mol} \mathrm{~L}^{-1}\right)$ por 4 min.

\section{Extração das substâncias húmicas aquáticas}

Amostras com elevados teores de matéria orgânica foram coletadas em afluentes dos rios Itapanhaú e Ribeira de Iguape, respectivamente. O rio Itapanhaú localiza-se no Parque Estadual da Serra do Mar (Latitude: $23^{\circ} 50^{\prime} 23^{\prime \prime S}$ e Longitude: $46^{\circ} 08^{\prime} 21^{\prime \prime W}$ ), situando-se na $7^{\text {a }}$ Unidade de Gerenciamento de Recursos Hídricos (UGRHIs) - Baixada Santista, município de Bertioga-SP. Já o rio Ribeira de Iguape localiza-se próximo à Estação Ecológica da Juréia (Latitude: $24^{\circ} 41^{\prime} 59^{\prime \prime S}$ e Longitude: $47^{\circ} 33^{\prime} 05^{\prime \prime} \mathrm{W}$ ), situando-se na $11^{\text {a }}$ Unidade de Gerenciamento de Recursos Hídricos - Ribeira do Iguape-litoral Sul, município de Iguape-SP.

Após coleta de cerca de 100 L de água em cada sítio em estudo, foram feitas caracterizações in situ das amostras, através das determinações de $\mathrm{pH}$, temperatura, oxigênio dissolvido e condutividade, após a calibração dos equipamentos, utilizando-se soluções padrões de referência. No laboratório, as amostras foram acidificadas a $\mathrm{pH} 2,0 \mathrm{com}$ solução de ácido clorídrico $6,0 \mathrm{~mol} \mathrm{~L}^{-1}$. A seguir, por gravidade, as amostras foram percoladas através de coluna de vidro $(2 \mathrm{~cm}$ de d.i. e 25 $\mathrm{cm}$ de altura) contendo resina Amberlite XAD 7 com fluxo de aproximadamente $8 \mathrm{~mL} \mathrm{~min}^{-1}$, conforme procedimento recomendado pela "International Humic Substances Society (IHSS)". Após saturação, verificada pelo escurecimento da resina, foi feita a eluição das SHA com solução de $\mathrm{NaOH} 0,1 \mathrm{~mol} \mathrm{~L}^{-1}$. O extrato húmico foi concentrado em rotaevaporador e seco em estufa com remoção de ar a $55^{\circ} \mathrm{C}$.

\section{Digestão das amostras}

$300 \mathrm{~mL}$ de amostras de água foram transferidos para béqueres de forma alta, adicionaram-se $10 \mathrm{~mL}$ de $\mathrm{HNO}_{3}$ (P.A. Merck, purificado por destilação) e aqueceu-se a mistura a $125^{\circ} \mathrm{C}$ até decomposição da matéria orgânica presente. Em seguida, o digerido foi transferido quantitativamente para balão volumétrico e o volume ajustado a $50 \mathrm{~mL}$ com água desionizada.

\section{Determinação de carbono orgânico}

As determinações do conteúdo de carbono orgânico total (COT) nas SHA foram feitas por combustão catalítica em corrente de oxigênio e subseqüiente detecção IR por analisador Schimadzu TOC500 com limite de detecção de (3s) $0,1 \mathrm{mg} \mathrm{L}^{-1}$ COT.

\section{Influência do pH e do tempo nas interações de metais e filtros de papel organomodificados}

Para estudo da complexação de metais pelo filtro de papel em função do $\mathrm{pH}$ foram utilizados $250 \mathrm{~mL}$ de solução padrão multielementar de metais $\left(\mathrm{Cu}, \mathrm{Mn}, \mathrm{Ni}\right.$ e Cd) $1,0 \mathrm{mg} \mathrm{L}^{-1}$, e o pH ajustado para 3,$0 ; 4,0 ; 5,0 ; 6,0$ e 7,0. Foram colocados filtros de papel modificados em contato com as soluções preparadas, e sob agitação mecânica foram retiradas alíquotas de $4 \mathrm{~mL}$ em função do tempo $(0 ; 2,5 ; 5 ; 10 ; 20 ; 30 ; 60 ; 120 ; 240 ; 360 ; 720 ; 1080$ e 1440 $\mathrm{min})$, as quais foram acidificadas e as concentrações dos metais determinadas por espectrometria de absorção atômica. As concentrações dos metais complexados pelo filtro de papel em função do tempo foram obtidas pela diferença entre as concentrações iniciais dos metais $(t=0)$ e as concentrações dos metais nas alíquotas retiradas nos diferentes intervalos de tempo.
Estudo das isotermas de adsorção em função da concentração de metal

O estudo da complexação de metais pelo filtro de papel em função da concentração de metal foi feito utilizando o método de batelada. Um filtro de papel modificado foi colocado em cubas de vidro contendo $250 \mathrm{~mL}$ de solução padrão multielementar de metais $(\mathrm{Cu}, \mathrm{Mn}, \mathrm{Ni}$ e $\mathrm{Cd})$ em diferentes concentrações de metal (0,5; 0,75; 1,0 e 2,0 $\mathrm{mg} \mathrm{L}^{-1}$ ), e pH 5,0. Retirou-se uma alíquota no tempo inicial $(\mathrm{t}=0)$ e outra alíquota após $12 \mathrm{~h}$ de agitação mecânica. As alíquotas foram acidificadas e as concentrações dos metais foram determinadas por espectrometria de absorção atômica. A concentração do metal adsorvido foi determinada pela diferença entre as concentrações iniciais e finais das alíquotas coletadas.

\section{Influência da concentração de matéria orgânica nas interações de metais e filtros de papel organomodificados}

Para avaliar a competição entre matéria orgânica e filtros de papel modificados pelos metais, preparou-se $250 \mathrm{~mL}$ de solução multielementar de metais $\left(\mathrm{Cu}, \mathrm{Mn}, \mathrm{Ni}\right.$ e Cd) $1,0 \mathrm{mg} \mathrm{L}^{-1}$, com diferentes concentrações de substâncias húmicas aquáticas $(15,30$ e 60 $\mathrm{mg} \mathrm{L}^{-1}$ ), ajustando-se o pH em 5,0. À solução colocaram-se filtros de papel modificados e retiraram-se alíquotas de $4 \mathrm{~mL}$ em função do tempo $(0 ; 2,5 ; 5 ; 10 ; 20 ; 30 ; 60 ; 120 ; 240 ; 360 ; 720 ; 1080$ e 1440 min), as quais foram acidificadas e as concentrações dos metais foram determinadas por espectrometria de absorção atômica. As concentrações dos metais complexados pelo filtro de papel em função do tempo foram obtidas pela diferença entre as concentrações iniciais dos metais $(\mathrm{t}=0)$ e as concentrações dos metais nas alíquotas retiradas nos diferentes intervalos de tempo.

\section{Influência do pH e presença da matéria orgânica nas interações de metais e filtros de papel organomodificados}

Para avaliar a competição entre matéria orgânica e o filtro de papel modificados pelos metais em função do $\mathrm{pH}$, preparou-se 250 $\mathrm{mL}$ de solução multielementar de metais ( $\mathrm{Cu}, \mathrm{Mn}, \mathrm{Ni}$ e Cd) $1,0 \mathrm{mg}$ $\mathrm{L}^{-1}$, com solução $15 \mathrm{mg} \mathrm{L}^{-1}$ de substâncias húmicas aquáticas, ajustando-se o pH para 3,0, 4,0, 5,0, 6,0 e 7,0. À solução foi colocado um filtro de papel modificado e retiradas alíquotas de $4 \mathrm{~mL}$ em função do tempo $(0 ; 2,5 ; 5 ; 10 ; 20 ; 30 ; 60 ; 120 ; 240 ; 360 ; 720 ; 1080$ e $1440 \mathrm{~min}$ ), as quais foram acidificadas e as concentrações dos metais determinadas por espectrometria de absorção atômica. As concentrações dos metais complexados pelo filtro de papel em função do tempo foram obtidas pela diferença entre as concentrações iniciais dos metais $(t=0)$, pelas concentrações dos metais nas alíquotas retiradas nos diferentes intervalos de tempo.

\section{Determinações de metais}

As determinações dos metais cobre, manganês, cádmio e níquel foram feitas por espectrômetro de absorção atômica com atomização por chama (Varian, AA240FS) e forno de grafite (Varian, AA240Z), dependendo da concentração original do elemento e seguindo as recomendações do fabricante.

\section{RESULTADOS E DISCUSSÃO}

A Tabela 1 apresenta resultados de caracterizações preliminares das amostras de água coletadas nos afluentes dos rios Itapanhaú e Ribeira de Iguape em outubro/2004 e abril/2005, respectivamente.

As coletas das amostras de água foram feitas em dois diferentes 
rios com elevadas concentrações de matéria orgânica, para se verificar a influência de fatores ambientais (por ex., umidade, temperatura, substrato, microorganismos etc.) na formação, decomposição, nas características estruturais da matéria orgânica e, conseqüentemente, na labilidade de espécies metálicas nos mananciais em estudo.

Observa-se pela Tabela 1 que a amostra de água coletada no rio Ribeira de Iguape apresentou concentração de carbono orgânico total (COT) cerca de 3 vezes maior que a do rio Itapanhaú, e bem acima dos valores encontrados em outros mananciais que, reconhecidamente, possuem elevada concentração de COT, por ex., o Rio Negro-AM (em média cerca de $\left.15 \mathrm{mg} \mathrm{L}^{-1}\right)^{6}$. Segundo Thurman ${ }^{13}$, a distribuição de carbono orgânico varia de 5 a $60 \mathrm{mg} \mathrm{L}^{-1}$ em águas naturais, sendo dependente da vazão do rio, clima, da vegetação, atividade microbiológica e das estações do ano. As concentrações de metais encontrados (Tabela 1) estão dentro das faixas observadas para mananciais com águas ricas em hidrocolóides húmicos, apresentando Mn como macroconstituinte e $\mathrm{Cu}, \mathrm{Cd}$ e $\mathrm{Ni}$ como microconstituintes.

Tabela 1. Caracterizações preliminares das amostras de água coletadas nos afluentes dos rios Itapanhaú e Ribeira de Iguape em outubro/2004 e abril/2005, respectivamente

\begin{tabular}{|c|c|c|}
\hline \multirow[t]{2}{*}{ Parâmetros analisados } & \multicolumn{2}{|c|}{ Amostras de água } \\
\hline & Itapanhaú & Ribeira de Iguape \\
\hline $\mathrm{pH}$ & 5,2 & 5,8 \\
\hline Temperatura $\left({ }^{\circ} \mathrm{C}\right)$ & 22,2 & 21,0 \\
\hline Condutividade $\left(\mu \mathrm{S} \mathrm{cm}^{-1}\right)$ & 73,2 & 303,0 \\
\hline Oxigênio dissolvido $\left(\mathrm{mg} \mathrm{L}^{-1}\right)$ & 3,7 & 5,1 \\
\hline Carbono orgânico total $\left(\mathrm{mg} \mathrm{L}^{-1}\right)$ & 12,3 & 37,8 \\
\hline Metal total & & \\
\hline Manganês $\left(\mu \mathrm{g} \mathrm{L}^{-1}\right)$ & 428,0 & 50,6 \\
\hline Cobre $\left(\mu \mathrm{g} \mathrm{L}^{-1}\right)$ & 3,5 & 3,2 \\
\hline Cádmio $\left(\mu \mathrm{g} \mathrm{L}^{-1}\right)$ & 2,67 & 1,3 \\
\hline Níquel $\left(\mu \mathrm{g} \mathrm{L}^{-1}\right)$ & 7,67 & 6,8 \\
\hline
\end{tabular}

O conhecimento do tempo de complexação necessário para a interação entre os metais e o filtro de papel organomodificado é um importante parâmetro a ser estudado, visando estudos de labilidade de metais em sistemas aquáticos. A Figura 1 ilustra a recuperação de metais no filtro de papel em $\mathrm{pH}$ 5,0, em função do tempo. A partir dos resultados obtidos verifica-se a seguinte ordem decrescente de afinidade dos metais pelo filtro de papel organomodificado: $\mathrm{Cu} \gg>\mathrm{Cd}>\mathrm{Ni}>\mathrm{Mn}$. Estes resultados mostraram a maior labilidade relativa de $\mathrm{Cu}$ e $\mathrm{Cd}$ em relação à $\mathrm{Mn}$ e $\mathrm{Ni}$, obedecendo a série de

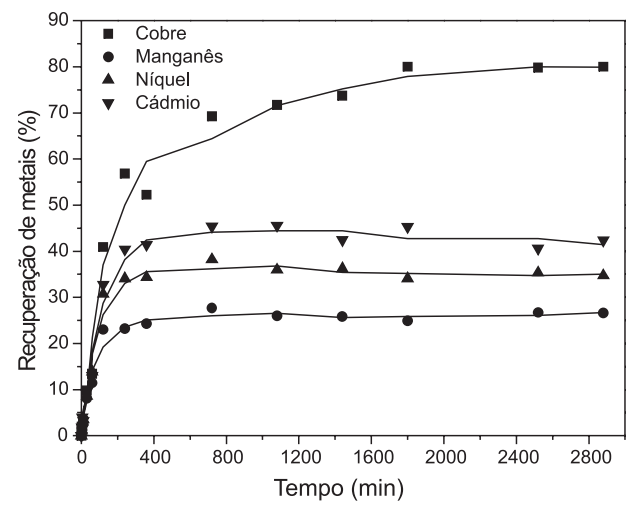

Figura 1. Recuperação de metais $(\mathrm{Cu}, \mathrm{Cd}, \mathrm{Mn}$ e $\mathrm{Ni})$ pelo filtro de papel modificado em função do tempo. Condições: $250 \mathrm{~mL}$ de solução contendo 1,0 $\mathrm{mg} \mathrm{L}^{-1}$ dos metais $\mathrm{Cu}, \mathrm{Cd}$, Mn e Ni, um filtro de papel modificado, $\mathrm{pH}$ 5,0 e agitação mecânica
Irving-Williams ${ }^{14}$, a qual explica a estabilidade de complexos metálicos, em função da variação do raio iônico pelo preenchimento dos orbitais $\mathrm{t}_{2} \mathrm{~g}$ e eg.

A partir dos resultados obtidos e do tratamento cinético (Figura 2), foi possível estimar o tempo de equilíbrio $\left(\mathrm{t}_{\mathrm{eq}}\right)$ necessário entre as espécies metálicas e o filtro de papel, na ausência de matéria orgânica. Os tempos de equilíbrio indicam uma cinética lenta para todos os metais $(\mathrm{Ni}=142, \mathrm{Mn}=151$ e $\mathrm{Cd}=194 \mathrm{~min})$, especialmente para o íon $\mathrm{Cu}(504 \mathrm{~min})$.

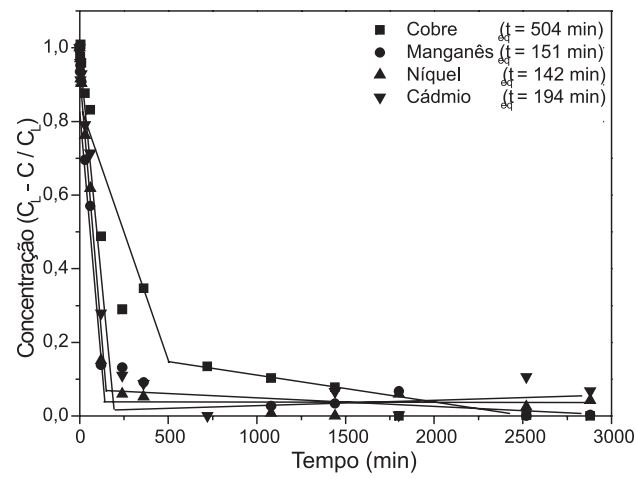

Figura 2. Estudo cinético das interações entre os metais e o filtro de papel modificado. Condições: $250 \mathrm{~mL}$ de solução contendo 1,0 $\mathrm{mg} \mathrm{L}^{-1}$ dos metais $\mathrm{Cu}, \mathrm{Cd}, \mathrm{Mn}$ e Ni, um filtro de papel modificado, $\mathrm{pH}$ 5,0 e agitação mecânica

A capacidade de adsorção de cátions pela superfície do papel de filtro organomodificado em soluções aquosas está baseada no par de elétrons livres presentes no átomo de nitrogênio, a qual é uma boa base de Lewis. Esta capacidade de adsorção foi avaliada através do comportamento de isotermas para os metais em estudo.

Quantitativamente, a adsorção pode ser expressa por parâmetros como $\mathrm{C}_{\mathrm{s}}$, concentração do soluto na solução, quando se estabelece o equilíbrio de adsorção, e $\mathrm{N}_{\mathrm{f}}$, número de mols de metal adsorvido, para $1 \mathrm{~g}$ do filtro de papel. Do ponto de vista experimental, o valor de $\mathrm{N}_{\mathrm{f}}$ foi obtido do número inicial de mols de cátion $\left(\mathrm{n}_{\mathrm{i}}\right)$ adicionado ao sistema e este no equilíbrio $\left(\mathrm{n}_{\mathrm{s}}\right)$ para a massa do filtro de papel em gramas (m), aplicando-se a seguinte expressão: $N_{f}=\left(n_{i}-n_{s}\right) /$ m. As isotermas de adsorção são mostradas na Figura 3.

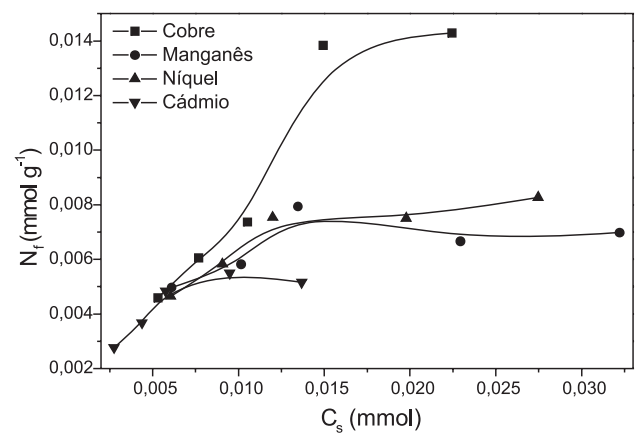

Figura 3. Isotermas de adsorção de metais pelo filtro de papel modificado no tempo de equilíbrio. Condições: $250 \mathrm{~mL}$ de solução multielementar contendo concentrações variadas de $\mathrm{Cu}, \mathrm{Mn}$, Ni e $\mathrm{Cd}$, um filtro de papel modificado, pH 5,0 agitação mecânica e tempo de complexação de $12 \mathrm{~h}$

A parte inicial da isoterma indica que, a adsorção é praticamente proporcional às concentrações de equilíbrio, com baixos valores para os parâmetros $\mathrm{N}_{\mathrm{f}}$ e $\mathrm{C}_{\mathrm{s}}$. Nessas condições, existem consideráveis porções de superfície adsorvente que ainda permanecem livres. Com o aumento da concentração do metal, a quantidade do material adsorvido 
na superfície sólida tende a um valor constante. Nessa situação, os sítios de adsorção na superfície do material adsorvente encontram-se completamente saturados e a quantidade de substância adsorvida não depende mais da concentração do metal.

Langmuir, em 1918, a fim de explicar fenômenos de adsorção, considerou que as moléculas adsorvidas fixavam-se na superfície do adsorvente em sítios definidos e localizados, onde cada sítio permitiria apenas uma entidade adsorvida e a energia correspondente seria a mesma em todos os sítios da superfície. Esse tipo de adsorção ocorre sempre que uma quantidade adsorvida atinge um valor máximo a uma determinada concentração e permanece constante. $\mathrm{O}$ processo completo de adsorção pode ser descrito quantitativamente por meio de isotermas de adsorção que, à temperatura constante, fornecem dados relacionados à quantidade adsorvida $\left(\mathrm{N}_{\mathrm{f}}\right)$ e à concentração do soluto $\left(\mathrm{C}_{\mathrm{s}}\right)$, depois de estabelecido o equilíbrio ${ }^{15,16}$.

A linearização das isotermas de adsorção foi feita com a aplicação da Equação de Langmuir (1)

$\frac{\mathrm{C}_{\mathrm{s}}}{\mathrm{N}_{\mathrm{f}}}=\frac{\mathrm{C}_{\mathrm{s}}}{\mathrm{N}_{\mathrm{s}}}+\frac{1}{\mathrm{~N}_{\mathrm{s}} \mathrm{k}}$

onde $\mathrm{C}_{\mathrm{s}}$ é a concentração em solução no equilíbrio $\left(m m o l \mathrm{~L}^{-1}\right), \mathrm{N}_{\mathrm{f}}$ foi definido anteriormente $\left(\mathrm{mmol} \mathrm{g}^{-1}\right), \mathrm{N}_{\mathrm{s}}$ é a quantidade máxima de soluto adsorvido por grama de superfície adsorvente $\left(\mathrm{mmol} \mathrm{g} \mathrm{g}^{-1}\right.$ ), que depende do número de sítios de adsorção e $\mathrm{k}$ é a medida de intensidade de adsorção, diretamente relacionada com uma constante de equilíbrio $\left(\mathrm{mol} \mathrm{L}^{-1}\right)$. A linearização das isotermas de adsorção foi plotada como apresentado na Figura 4.

$\mathrm{O}$ gráfico de $\mathrm{C} / \mathrm{N}_{\mathrm{f}}$ plotadas em função de $\mathrm{C}_{\mathrm{s}}$ resultam em retas de coeficiente angular $1 / \mathrm{Ns}$ e coeficiente linear $1 /(\mathrm{Nk})$, sendo possível calcular os valores das constantes $\mathrm{k}$ e $\mathrm{N}_{\mathrm{s}}$ para cada interação superfície-cátion.

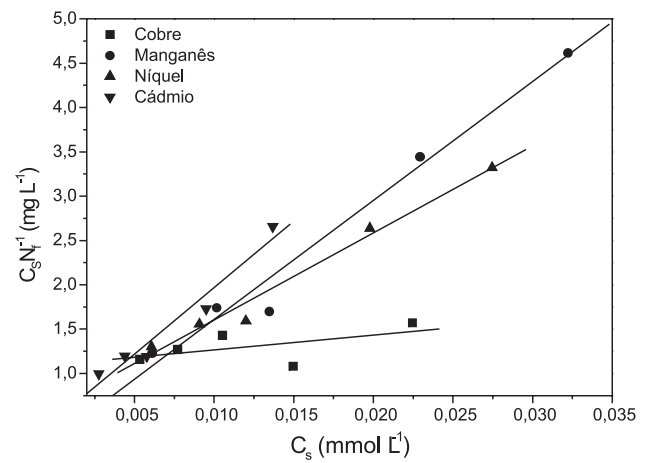

Figura 4. Isotermas linearizadas de adsorção de metais pelo filtro de papel modificado no tempo de equilíbrio em $\mathrm{pH}$ 5,0

A partir dos resultados apresentados na Figura 4, obtidos pelas isotermas linearizadas de adsorção de metais em pH 5,0, observase comportamento distinto para cada metal. A Tabela 2 apresenta os parâmetros calculados, usando-se a Equação de Langmuir, da adsorção em solução $\left(\mathrm{N}_{\mathrm{s}}\right)$ dos metais estudados sobre o filtro de papel modificado.

Verifica-se maior adsorção em mmols de $\mathrm{Cu}, \mathrm{Ni}, \mathrm{Mn}$, e Cd, respectivamente, por grama de adsorvente quando se observam os valores de Ns. Ou seja, Cd(II) é o cátion que apresenta menor quantidade de grupos internos acessíveis à sua retenção no papel de filtro. Comparandose a capacidade de retenção com os dados de $\mathrm{Britto}^{15}$, que estudou a retenção de metais por sílicas organomodificadas, os valores são bem mais baixos. Porém, considerando as baixas concentrações de metais originalmente presentes em sistemas aquáticos, o papel de filtro organomodificado apresenta-se como um suporte adequado.
Tabela 2. Parâmetros calculados para adsorção em solução de espécies metálicas

\begin{tabular}{lcrcc}
\hline Metais & $1 / \mathrm{N}_{\mathrm{s}} \mathrm{k}$ & \multicolumn{1}{c}{$1 / \mathrm{N}_{\mathrm{s}}$} & $\mathrm{N}_{\mathrm{s}}\left(10^{-3} \mathrm{mmol} \mathrm{g}^{-1}\right)$ & $\mathrm{k}\left(10^{3}\right)$ \\
\hline $\mathrm{Cu}$ & 1,08 & 26,46 & 37,80 & 0,02 \\
$\mathrm{Mn}$ & 0,03 & 134,12 & 7,46 & 5,00 \\
$\mathrm{Ni}$ & 0,62 & 98,12 & 10,19 & 0,16 \\
$\mathrm{Cd}$ & 0,47 & 149,88 & 6,67 & 0,32 \\
\hline
\end{tabular}

As formas linearizadas das isotermas permitem calcular os valores de intensidade de adsorção, onde a constante $\mathrm{k}$ apresentou valores elevados para todos os complexos formados. Pode-se admitir que a constante $\mathrm{k}$ é proporcional ao valor da constante de equilíbirio. De acordo com a ordem de grandeza da constante k, sugere-se que os complexos formados são termodinamicamente estáveis, apoiando-se nos valores de coeficientes de correlação das retas, confirmando o modelo de adsorção proposto.

Comparando-se os valores de $\mathrm{k}$, para os metais, observa-se que em $\mathrm{pH}$ 5,0 o Mn forma complexos bem mais estáveis com o filtro de papel em relação a Ni e Cd. Já pelo valor de k $(0,02)$ para $\mathrm{Cu}$, verifica-se a baixa estabilidade do complexo.

A Figura 5 exemplifica a complexação observada para os metais $\mathrm{Cd}, \mathrm{Cu}, \mathrm{Mn}$ e Ni em função do tempo para diferentes valores de $\mathrm{pH}(3,0 ; 4,0 ; 5,0 ; 6,0$ e 7,0). Observou-se forte influência do $\mathrm{pH}$ no processo de complexação de metais pelo filtro de papel, de acordo com a espécie metálica estudada. A complexação de Mn, Ni e Cd para os diferentes valores de $\mathrm{pH}$ mostrou um comportamento semelhante e crescente com o aumento do valor de $\mathrm{pH}$. Já para o íon $\mathrm{Cu}$ a ordem verificada foi $3<4<7<5=6$. Este comportamento está provavelmente associado à variação das espécies de hidroxo-complexos formados que facilitam a mobilidade em solução, a difusão através da membrana e, conseqüentemente, a complexação do metal pelo filtro de papel. Também, em baixos valores de $\mathrm{pH}$ ocorre a protonação do grupo amino, provocando a repulsão das espécies metálicas, dificultando o processo de interação entre os metais e os grupos reativos do filtro de papel organomodificado.

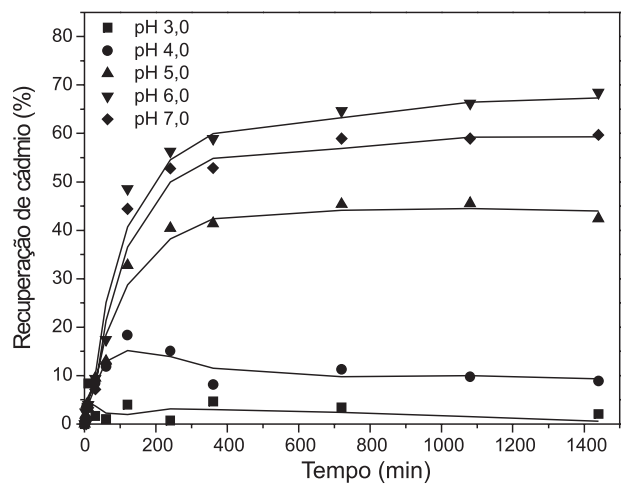

Figura 5. Recuperação de cádmio pelo filtro de papel modificado em função do tempo, para diferentes valores de pH. Condições: $250 \mathrm{~mL}$ de solução contendo 1,0 mg $\mathrm{L}^{-1}$ de $\mathrm{Cd}$, um filtro de papel modificado, valores de $\mathrm{pH}$ 3,0; 4,0; 5,0; 6,0; 7,0 e agitação mecânica

A Figura 6 compara a capacidade de complexação dos metais $\mathrm{Cd}, \mathrm{Cu}, \mathrm{Mn}$ e Ni após 24 h de complexação em diferentes valores de $\mathrm{pH}$. A capacidade de complexação entre $\mathrm{Cu}, \mathrm{Cd}, \mathrm{Ni}$ e $\mathrm{Mn}$ e o filtro de papel apresentou valores baixos em $\mathrm{pH} 3,0$ (de 0 a 5\%) e maiores em pH 6,0 (55 a 82\%).

Os parâmetros tempo e concentração de matéria orgânica foram estudados em relação à labilidade de espécies metálicas, utilizan- 


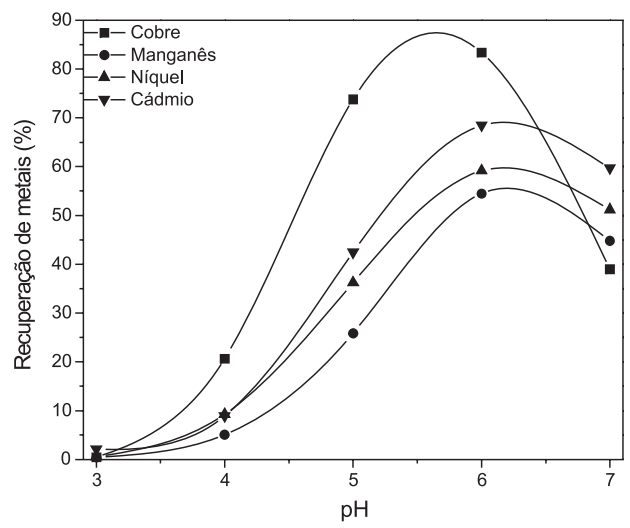

Figura 6. Recuperação de metais pelo filtro de papel modificado após tempo de complexação de $24 \mathrm{~h}$, para diferentes valores de $\mathrm{pH}$. Condições: $250 \mathrm{~mL}$ de solução contendo $1,0 \mathrm{mg} \mathrm{L}^{-1}$ de $\mathrm{Cu}, \mathrm{Cd}$, Mn e Ni, um filtro de papel modificado, valores de pH 3,0; 4,0; 5,0; 6,0; 7,0, agitação mecânica e tempo de complexação de $24 \mathrm{~h}$

do-se filtro de papel organomodificado. Os resultados obtidos foram importantes para avaliação, em laboratório, de como os parâmetros estudados influenciariam em experimentos a serem realizados in situ.

As características estruturais da MON, especialmente das SHA (principal fração), influenciam diretamente na labilidade de metais em recursos hídricos. Assim, foram estudadas amostras de SHA extraídas de amostras de água coletadas em duas regiões distintas, localizadas em afluentes dos rios Itapanhaú e Ribeira de Iguape, para se verificar a influência das característica das SHA na labilidade de metais.

O tempo é um parâmetro que influencia a reatividade de metais complexados com a matéria orgânica natural, devido aos possíveis processos de transformação que ocorrem com as espécies complexadas recém-formadas. Qualitativamente, os íons metálicos recentemente ligados às SHA são preferencialmente complexados por grupos funcionais de maior acessibilidade na macromolécula ${ }^{17}$. Ao longo do tempo, parte dos íons metálicos pode migrar para sítios ligantes mais internos da macromolécula orgânica. Este rearranjo dos íons metálicos na macromolécula húmica flexível aumenta o grau de condensação macromolecular, tornando menos lábeis ${ }^{2}$ os metais complexados com sítios mais internos.

A influência do tempo de complexação, também definida como processo de envelhecimento ("ageing"), sobre a labilidade dos íons $\mathrm{Cd}, \mathrm{Cu}, \mathrm{Mn}$ e Ni para a amostra de SHA extraída de amostra de água coletada em afluente no rio Itapanhaú (SHA-Itapanhaú) é mostrada na Figura 7. Os diferentes tempos de equilíbrio observados para os íons em estudo estão associados às suas diferentes afinidades pelos grupos reativos das SHA e do filtro de papel organomodificado $(\mathrm{Mn}=30, \mathrm{Ni}=120, \mathrm{Cd}=360$ e $\mathrm{Cu}=720 \mathrm{~min})$. Já as SHA extraídas de amostra de água coletada em afluente do Rio Ribeira de Iguape (SHA-Ribeira de Iguape), mostraram aumento da capacidade de complexação com o aumento do tempo, apresentando equilíbrio em $12 \mathrm{~h}$ para $\mathrm{Cu}$, e $6 \mathrm{~h}$ para $\mathrm{Mn}$, Ni e $\mathrm{Cd}$. A partir dos resultados obteve-se a seguinte ordem crescente de capacidade de complexação $\mathrm{Mn}<\mathrm{Ni}=\mathrm{Cd}<<\mathrm{Cu}$, conforme mostra a Figura 8.

A recuperação de metais pelo filtro de papel modificado na presença de SHA-Ribeira de Iguape foi menor que a recuperação de metais na presença de SHA-Itapanhaú. Na presença de SHAItapanhaú, os íons metálicos Mn e Ni alcançaram o equilíbrio mais rapidamente em 30 e $120 \mathrm{~min}$, respectivamente. Já SHA-Ribeira de Iguape o $\mathrm{t}_{\mathrm{eq}}$ foi maior para estes dois íons (Mn e $\mathrm{Ni}$ ), enquanto para $\mathrm{Cd}$ e $\mathrm{Cu}$ não houve alteração nos valores de $\mathrm{t}_{\mathrm{eq}}$. Estes resultados con-

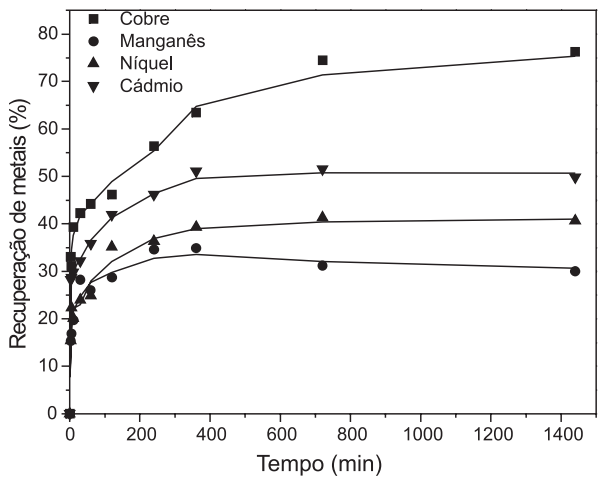

Figura 7. Influência do tempo na labilidade relativa de íons metálicos. Condições: $250 \mathrm{~mL}$ de solução contendo $1,0 \mathrm{mg} \mathrm{L}^{-1}$ dos metais $\mathrm{Cu}, \mathrm{Cd}$, Mn e $\mathrm{Ni}$, concentração de SHA-Itapanhaú $15 \mathrm{mg} \mathrm{L}^{-1}$, filtro de papel modificado, pH 5,0 e agitação mecânica.

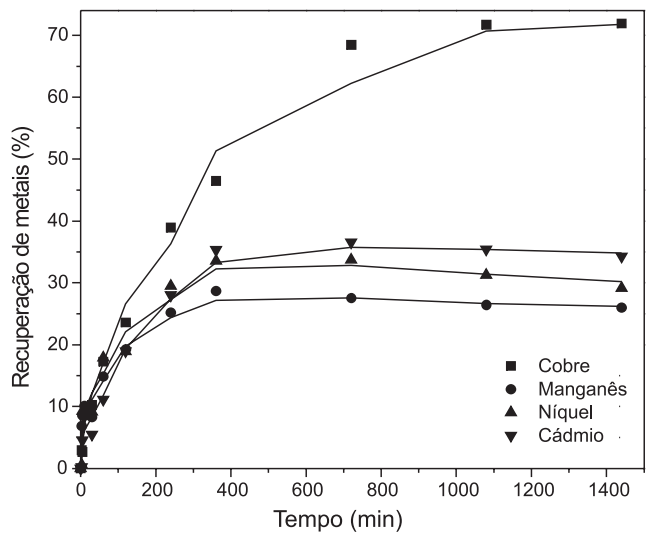

Figura 8. Influência do tempo na labilidade relativa de íons metálicos. Condições: $250 \mathrm{~mL}$ de solução contendo 1,0 $\mathrm{mg} \mathrm{L}^{-1}$ dos metais $\mathrm{Cu}, \mathrm{Cd}$, Mn e $\mathrm{Ni}$, concentração de SHA-Ribeira de Iguape $15 \mathrm{mg} \mathrm{L}^{-1}$, filtro de papel modificado, pH 5,0 e agitação mecânica.

firmam a hipótese de que a labilidade de espécies metálicas é fortemente influenciada pelas características estruturais das SHA, as quais formam complexos de diferentes estabilidades para cada metal.

A capacidade de complexação do metal pelas SHA e a estabilidade termodinâmica de suas espécies variam consideravelmente em função de diferentes parâmetros experimentais ${ }^{11}$. A estabilidade termodinâmica e a cinética de complexos SHA-metal é altamente dependente da razão massa de metais/massa de SHA e da capacidade de complexação da SHA ${ }^{1,2}$.

Em princípio, a troca de íons metálicos entre o filtro de papel e a fração metálica lábil de complexos macromoleculares com SHAmetal pode ser descrita pelo seguinte equilíbrio:

SHA-M + filtro de papel $\rightleftharpoons$ M-filtro de papel + SHA

onde SHA-M indica as espécies formadas entre os íons metálicos e a SHA e M-filtro de papel indica as espécies formadas entre o íon metálico e o filtro de papel.

Assim, as concentrações das espécies SHA-M e M-filtro de papel alteram-se em função do aumento da concentração de substâncias húmicas aquáticas.

O comportamento da labilidade dos íons metálicos estudados foi distinto na presença de substâncias húmicas extraídas das amostras coletadas nos dois diferentes pontos de coleta, como está resumido na Tabela 3 . 
Para Mn, Ni e Cd, o aumento da concentração de SHA-Ribeira de Iguape não interferiu na labilidade do metal. $\mathrm{Cu}$ apresentou uma diminuição na recuperação de metais com o filtro de papel quando a concentração de SHA-Ribeira de Iguape foi aumentada para $60 \mathrm{mg} \mathrm{L}^{-1}$.

$\mathrm{Cu}, \mathrm{Mn}, \mathrm{Ni}$ e $\mathrm{Cd}$ apresentaram uma diminuição na capacidade de complexação com o filtro de papel quando a concentração de SHA-Itapanhaú foi aumentada. Isto ocorre pois, aumentando-se a concentração de SHA, o equilíbrio é deslocado na direção do favorecimento das espécies SHA-metal, explicando a ocorrência de valores de recuperação de metais menores em soluções concentradas de SHA. Isto ocorre, provavelmente, devido ao fato da macromolécula húmica apresentar elevado grau de condensação em solução concentrada de SHA, tornando os metais menos acessíveis ao contato com os sítios complexantes do filtro de papel.

A Tabela 4 compara as porcentagens de metais lábeis na ausência e presença de SHA-Itapanhaú e SHA-Ribeira de Iguape (15 mg $\mathrm{L}^{-1}$ ), em diferentes valores de $\mathrm{pH}$ após $24 \mathrm{~h}$. Observa-se que a SHAItapanhaú, apresentou valores máximos de complexação em pH 6,0, enquanto que para as SHA-Ribeira de Iguape, os valores máximos foram encontrados em $\mathrm{pH} 7,0$.

\section{CONCLUSÕES}

A análise das curvas obtidas nos estudos de equilíbrio de sorção dos íons $\mathrm{Cu}, \mathrm{Mn}$, Ni e $\mathrm{Cd}$ em meio aquoso com o filtro de papel organomodificado permitiu que tirassem as seguintes conclusões: a partir dos resultados obtidos da recuperação de metais $(\mathrm{Cd}, \mathrm{Cu}, \mathrm{Mn}$ e
Ni) em pH 5,0, em função do tempo, verificou-se a seguinte ordem decrescente de afinidade dos metais pelo filtro de papel organomodificado: $\mathrm{Cu} \gg \mathrm{Cd}>\mathrm{Ni}>\mathrm{Mn}$. Os tempos de equilíbrio necessários entre espécies metálicas e o filtro de papel organomodificado na ausência de matéria orgânica indicaram uma cinética lenta para o íon $\mathrm{Cu}$ (504 min) e mais rápidas para os demais $(\mathrm{Ni}=142, \mathrm{Mn}=151$ e Cd = 194 min). Para Mn, Ni e Cd, o aumento da concentração de SHA-Ribeira de Iguape não interferiu na labilidade do metal. Cu apresentou uma diminuição na recuperação com o filtro de papel organomodificado quando a concentração de SHA-Ribeira de Iguape foi aumentada para $60 \mathrm{mg} \mathrm{L}^{-1}$. $\mathrm{Cu}, \mathrm{Mn}, \mathrm{Ni}$ e $\mathrm{Cd}$ apresentaram uma diminuição na capacidade de complexação com o filtro de papel organomodificado, quando a concentração de SHA-Itapanhaú foi aumentada. Observou-se que os íons metálicos $\mathrm{Cu}, \mathrm{Mn}, \mathrm{Ni}$ e $\mathrm{Cd}$ no filtro de papel, na ausência de SHA e na presença de SHA-Itapanhaú, apresentaram um valor máximo em $\mathrm{pH}$ 6,0, e na presença de SHARibeira de Iguape, os valores máximos encontrados foram em $\mathrm{pH}$ 7,0. A partir dos resultados obtidos, verificou-se que a utilização de papel de filtro organomodificado apresenta-se como uma alternativa interessante e promissora visando sua utilização em experimentos in-situ para caracterização da labilidade de espécies metálicas em sistemas aquáticos.

\section{AGRADECIMENTOS}

À FAPESP, CNPq, CAPES e FUNDUNESP por bolsas e suporte financeiro.

Tabela 3. Comparação entre as porcentagens de metais complexados pelo filtro de papel organomodificado na ausência e presença de diferentes concentrações de substâncias húmicas aquáticas (15-60 mg L L $\left.{ }^{-1}\right)$ após $24 \mathrm{~h}$

\begin{tabular}{|c|c|c|c|c|c|c|c|c|}
\hline \multirow{3}{*}{$\begin{array}{l}\text { Concentração } \\
\left.\text { de SHA (mg L }{ }^{-1}\right)\end{array}$} & \multicolumn{8}{|c|}{ Recuperação de metais (\%) } \\
\hline & \multicolumn{4}{|c|}{ Ribeira de Iguape } & \multicolumn{4}{|c|}{ Itapanhaú } \\
\hline & $\mathrm{Cu}$ & $\mathrm{Mn}$ & $\mathrm{Ni}$ & $\mathrm{Cd}$ & $\mathrm{Cu}$ & $\mathrm{Mn}$ & $\mathrm{Ni}$ & $\mathrm{Cd}$ \\
\hline Ausência de SHA & 73,8 & 25,8 & 36,2 & 42,4 & 73,8 & 25,8 & 36,2 & 42,4 \\
\hline 15 & 71,9 & 26,0 & 29,1 & 34,3 & 76,2 & 30,1 & 40,7 & 49,8 \\
\hline 30 & 75,8 & 28,0 & 36,8 & 37,9 & 61,2 & 26,7 & 27,2 & 43,1 \\
\hline 60 & 38,4 & 23,8 & 40,4 & 41,0 & 46,5 & 20,9 & 24,3 & 32,5 \\
\hline
\end{tabular}

Condições: $250 \mathrm{~mL}$ de solução contendo $1,0 \mathrm{mg} \mathrm{L}^{-1} \mathrm{de} \mathrm{Cu}, \mathrm{Cd}, \mathrm{Mn}$ e Ni, ausência e presença de diferentes concentrações de SHA-Itapanhaú e SHA-Ribeira de Iguape (15, 30 e $\left.60 \mathrm{mg} \mathrm{L}^{-1}\right)$, filtro de papel organomodificado, pH 5,0 e agitação mecânica.

Tabela 4. Comparação entre as porcentagens de metais complexados pelo filtro de papel organomodificado na ausência e presença de SHAItapanhaú e SHA-Ribeira de Iguape $\left(15 \mathrm{mg} \mathrm{L}^{-1}\right)$, em diferentes valores de $\mathrm{pH}$ após $24 \mathrm{~h}$

\begin{tabular}{|c|c|c|c|c|c|c|}
\hline \multirow[t]{2}{*}{ Metal } & \multirow{2}{*}{$\begin{array}{l}\text { Ausência/presença } \\
\text { de SHA }\left(15 \mathrm{mg} \mathrm{L}^{-1}\right)\end{array}$} & \multicolumn{5}{|c|}{ Recuperação de metais (\%) } \\
\hline & & $\mathrm{pH} 3$ & $\mathrm{pH} 4$ & pH 5 & $\mathrm{pH} 6$ & $\mathrm{pH} 7$ \\
\hline \multirow[t]{3}{*}{$\mathrm{Cu}$} & Ausência & 0,44 & 20,64 & 73,78 & 83,36 & 38,96 \\
\hline & SHA-Itapanhaú & 4,36 & 50,20 & 76,22 & 89,70 & 11,89 \\
\hline & SHA-Ribeira de Iguape & 5,24 & 21,02 & 71,89 & 90,21 & 93,85 \\
\hline \multirow[t]{3}{*}{ Mn } & Ausência & 0,44 & 5,08 & 25,84 & 54,47 & 44,82 \\
\hline & SHA-Itapanhaú & 0,55 & 5,94 & 30,06 & 40,29 & 4,06 \\
\hline & SHA-Ribeira de Iguape & 6,60 & 11,78 & 26,02 & 35,21 & 55,85 \\
\hline \multirow[t]{3}{*}{$\mathrm{Ni}$} & Ausência & 0,53 & 9,24 & 36,23 & 59,12 & 51,17 \\
\hline & SHA-Itapanhaú & 4,47 & 18,31 & 40,65 & 54,88 & 14,51 \\
\hline & SHA-Ribeira de Iguape & 2,25 & 4,21 & 29,12 & 53,89 & 76,21 \\
\hline \multirow[t]{3}{*}{$\mathrm{Cd}$} & Ausência & 2,05 & 8,90 & 42,43 & 68,43 & 59,68 \\
\hline & SHA-Itapanhaú & 2,71 & 27,90 & 49,82 & 53,32 & 7,73 \\
\hline & SHA-Ribeira de Iguape & 3,48 & 8,44 & 34,26 & 54,16 & 69,51 \\
\hline
\end{tabular}

Condições: $250 \mathrm{~mL}$ de solução contendo $1,0 \mathrm{mg} \mathrm{L}^{-1} \mathrm{de} \mathrm{Cu}, \mathrm{Cd}, \mathrm{Mn}$ e Ni, ausência e presença de SHA-Itapanhaú e SHA-Ribeira de Iguape $\left(15 \mathrm{mg} \mathrm{L}^{-1}\right)$, filtro de papel organomodificado, $\mathrm{pH} 3,0 ; 4,0 ; 5,0 ; 6,0$ e 7,0 e agitação mecânica. 


\section{REFERÊNCIAS}

1. Rocha, J. C.; Rosa, A. H.; Cardoso, A. A.; Introdução à Química Ambiental, BOOKMAN: Porto Alegre, 2004.

2. Rocha, J. C.; Rosa, A. H.; Substâncias húmicas aquáticas: interações com espécies metálicas, UNESP: São Paulo, 2003.

3. Rosa, A. H.; Rocha, J. C.; Sargentini Jr., E. Em Understanding and managing organic matter in soils, sediments and waters; Swift, R. S.; Spark, K. M., eds.; New York, 2001, p. 41-46.

4. Rosa, A. H.; Rocha, J. C.; Furlan, M.; Quim. Nova 2000, 23, 472.

5. Rocha, J. C.; Sargentini Jr., E.; Zara, L. F.; Rosa, A. H.; Santos, A.; Burba, P.; Talanta 2000, 53, 551

6. Rocha, J. C.; Sargentini Jr., E.; Zara, L. F.; Rosa, A. H.; Santos, A.; Burba, P.; Talanta 2003, 61, 699.

7. Rosa, A. H.; Rocha, J. C.; Burba, P.; Talanta 2002, 58, 969.

8. Burba, P.; Willmer, P. G.; Fresenius J. Anal. Chem. 1992, 342, 167.

9. Burba, P.; Fresenius J. Anal. Chem. 1994, 348, 301.
10. Lu, Y. J.; Chakrabarti, C. L.; Int. J. Environ. Anal. Chem. 1995, 60, 313

11. Buffle, J.; Complexation reactions in aquatic systems: an analytical approach, New York: Ellis Horwood, 1990.

12. Buffle, J.; Horvai, G.; In situ monitoring of aquatic systems: Chemical analysis and speciation, John Wiley \& Sons: New York, 2000.

13. Thurman, E. M. Em Humic substances in soil, sediment and water geochemistry, isolation and characterization; Aiken, G. R.; Mcknight, D. M.; Wershaw, R. L.; Maccarthy, P., eds.; John Wiley \& Sons: New York, 1985 , p. 87-104.

14. Huheey, J. E.; Keiter, E. A.; Keiter, R. L.; Inorganic chemistry: principles of structure and reactivity, $4^{\text {th }}$ ed.; Harper Collins College Publischers: New York, 1993.

15. Britto, P. F.; Dissertação de Mestrado, Universidade Estadual Paulista, Brasil, 2005

16. Torres, J. D.; Faria, E. A.; Prado, A. G. S.; J. Hazard Mater. 2006, 129, 239.

17. Burba, P.; Rocha, J. C.; Klockow, D.; Fresenius J. Anal. Chem. 1994, 349, 800. 